30. Canberra: Commonwealth Department of Human Services and Health, 1996.

3. Ministerial Council on Drug Strategy. National drug strategic framework 1998-99 to 2002-03. Canberra: Ministerial Council on Drug Strategy, 1998.

4. NSW Drug Summit 1999. Government Plan of Action. Sydney: NSW Government, 1999. ISBN 73135400 1. 师
Further information on national statistics, response rates, estimation procedures, reliability of estimates and comparability to the 1995 survey are available in the AIHW Drug Statistics Series, ${ }^{1}$ which is also accessible on the AlHW internet site www.aihw.gov.au.

\title{
GENERAL PRACTICE ACTIVITY IN AUSTRALIA 1998-1999
}

\section{Associate Professor Helena Britt}

Director, Family Medicine Research Centre

University of Sydney

A report of the first year's data from the Bettering the Evaluation And Care of Health program (BEACH), a continuous national survey of general practice activity, was released recently by the General Practitioners Statistics and Classification Unit. The unit is a collaborating unit of the University of Sydney's Family Medicine Research Centre and the Australian Institute of Health and Welfare. The program began in April 1998 and is currently funded by a consortium of six organisations: the Commonwealth Department of Health and Aged Care, the Department of Veterans' Affairs, the National Occupational Health and Safety Commission, AstraZeneca Australia, Roche Products, and Rhône Poulenc Rorer. It aims to provide an up-to-date source of information about the patients seen in general practice, the problems managed, and the treatments provided. This article describes the rationale for the collection of the data and some of the preliminary results.

Because about 85 per cent of the population visit a general practitioner (GP) in any one year, general practice data can provide a good indication of the health of the community. ${ }^{1}$ Each year, approximately 1,000 randomly selected GPs participate in BEACH. Each GP records the details of 100 consecutive doctor-patient encounters (any professional interchange between a patient and a general practitioner). The first year's data set includes information about 96,901 such consultations (after post-stratification weighting). Reasons for the encounter, problems managed, referrals, non-pharmacological management and investigations are classified according to the ICPC-2: International Classification of Primary Care (Version 2), ${ }^{2}$ and coded more specifically in ICPC-2 PLUS. ${ }^{3}$ Prescribed pharmaceuticals are coded to brand level. They are classified according to an in-house classification, the Coding Atlas for Pharmaceutical Substances and to the Anatomical Therapeutic Chemical Classification Index. ${ }^{4}$ Additional data elements include strength of prescribed drug and regimen (course of therapy) from which one can derive a prescribed daily dose.

The BEACH relational database is described diagrammatically in Figure 1. All variables can be directly related to GP and patient characteristics and to the encounter. Reasons for encounters have only an indirect relationship with problems managed. All types of management are directly related to the problem being treated.

At the majority of encounters (57.7 per cent), the patient was female, and approximately 25 per cent were in each of the following age groups: < 25 years, 25-44 years, 4564 years and $65+$ years. The patient was new to the practice in 9.2 per cent of encounters. Almost half the encounters were with patients who held some form of health care concession card (47.3 per cent) and a further 3.4 per cent were with persons who held a Department of Veterans' Affairs concession card. Patients from a non-English speaking background represented 14.5 per cent of encounters. Information was also collected on consultations with indigenous people.

The most common reasons for a patient to initiate an encounter were a need for a prescription, a check-up, and immunisation-vaccination, together with symptoms such as cough, throat and back complaints.

Problems $(\mathrm{N}=140,824)$ were managed at a rate of 145 per 100 encounters and almost half of these were new to the patient. The problems most often managed in general practice were respiratory or musculoskeletal in nature or associated with the skin or the cardiovascular system. (Table 4). The most common individual problems were hypertension ( 8.3 per 100 encounters), upper respiratory tract infection (6.8) and immunisation-vaccination (5.2 per 100). Depression (3.5 per 100 encounters) had risen from tenth to fourth in relative frequency since 1990-91, while immunisation-vaccination had risen from sixth to third position. ${ }^{5}$ The GPs regarded 2.7 per cent of all problems to be work-related.

Medications were prescribed (85.3 per cent), advised for over the counter purchase, or supplied by the GP at a rate 
FIGURE 1

THE BEACH RELATIONAL DATABASE

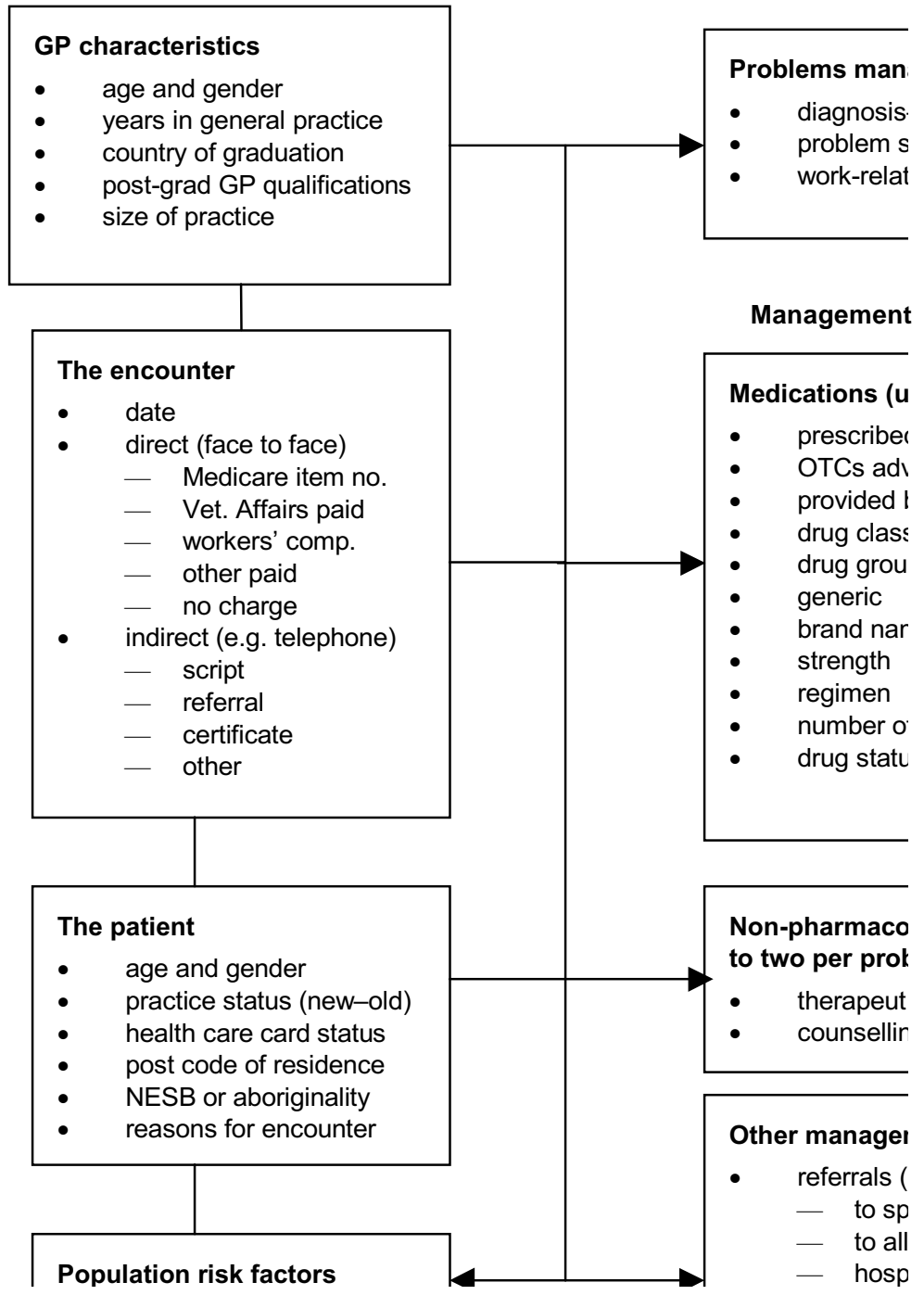

Source: General practice activity in Australia 1998-99. ${ }^{6}$

of 109 per 100 encounters, or 75 per 100 problems managed. Approximately half the problems were managed without a prescribed medication. Commonly prescribed medication groups included antibiotics (17.8 per cent), drugs for cardiovascular treatment (14.8 per cent) and for the central nervous system (12.0 per cent). The most frequently prescribed individual medications were paracetamol (five per cent of medications), amoxycillin (three per cent), and paracetamol or codeine (2.7 per cent). Considerable change had occurred since 1990-91 in prescribing patterns, particularly where new medications had become available.

Non-pharmacological problem management was provided at a rate of 25.4 per 100 encounters, and these were more commonly clinical (for example, advice and counselling) than procedural in nature. 


\section{TABLE 4}

\section{DISTRIBUTION OF PROBLEMS MANAGED ACROSS ICPC-2}

\begin{tabular}{|lcc|}
\hline Problem managed & $\begin{array}{c}\text { Rate per 100 } \\
\text { encounters (N=96,901) }\end{array}$ & $\begin{array}{c}\text { 95\% confidence } \\
\text { intervals }\end{array}$ \\
\hline Respiratory & 24.3 & $(23.6-25.0)$ \\
Musculoskeletal & 16.9 & $(16.3-17.5)$ \\
Skin & 16.5 & $(16.0-17.0)$ \\
Circulatory & 16.1 & $(15.4-16.8)$ \\
General \& unspecified & 13.2 & $(12.7-13.7)$ \\
Psychological & 10.5 & $(10.0-11.0)$ \\
Digestive & 10.2 & $(9.9-10.5)$ \\
Endocrine \& metabolic & 8.8 & $(8.4-9.2)$ \\
Female genital system & 6.3 & $(5.9-6.6)$ \\
Ear & 4.9 & $(4.7-5.1)$ \\
Pregnancy \& family planning & 4.1 & $(3.7-4.4)$ \\
Neurological & 4.0 & $(3.8-4.2)$ \\
Urology & 2.8 & $(2.7-3.0)$ \\
Eye & 2.8 & $(2.7-3.0)$ \\
Blood & 1.7 & $(1.5-1.9)$ \\
Male genital system & 1.4 & $(1.3-1.5)$ \\
Social problems & 0.8 & $(0.6-0.9)$ \\
Total problems & 145.3 & $(143.5-147.2)$ \\
\hline Figures do not total 100\% because more than one problem may have been managed & \\
at each encounter. & & \\
Source: General practice activity in Australia 1998-99.6 & \\
\hline
\end{tabular}

The patient was referred to another health professional at 7.8 per cent of encounters. Referrals to specialists ( 7.4 per 100 encounters) outnumbered those to allied health professionals (3.0 per 100), referrals to surgeons and physiotherapists being most common in each group. Hospital admissions were arranged at a rate of 0.7 per 100 encounters, suggesting that more than 700,000 such admissions are organised nationally by GPs each year. GPs ordered at least one pathology test at 13.2 per cent of encounters, while imaging was ordered at 6.3 per cent.

A breakdown of encounters by state based on the patient's postcode of residence demonstrated sufficient sample size for New South Wales, Victoria, Queensland and Western Australia to conduct individual state-based analysis. Encounters with patients resident in New South Wales numbered 35,768, and an overview of the NSW data-set is provided in the report.

\section{CONCLUSION}

The potential usefulness of this rich database is immense for those interested in health services research, population health, health economics or quality of health care. The data can be combined with hospital separation data, Australian Bureau of Statistics National Health Survey data, NSW Health Survey data, and other health information to provide a more comprehensive picture of the health of the community.

\section{REFERENCES}

1. Deeble J. Medical Services Through Medicare. National Health Strategy Background Papers, Macklin J, ed. Canberra: National Health Strategy Unit, 1991.

2. Classification Committee of the World Organization of Family Doctors 1997. ICPC-2: International Classification of Primary Care (Version 2). Oxford University Press, 1997.

3. Britt $\mathrm{H}$. A new coding tool for computerised clinical systems in primary care-ICPC PLUS. Aust Fam Physician 1997; 26 (Suppl. 2): S79-S82.

4. WHO Collaborating Centre for Drug Statistics Methodology. Anatomical Therapeutic Chemical (ATC) classification index with defined daily doses (DDDs). Oslo: World Health Organization, 1998.

5. Bridges-Webb C, Britt H, Miles DA, Neary S, Charles J, Traynor V. Morbidity and treatment in general practice in Australia 1990-1991. Med J Aust 1992; 157: S1-S56.

6. Britt H, Sayer GP, Miller GC, Charles J, et al. General practice activity in Australia 1998-99. Canberra: Australian Institute of Health and Welfare, 1999. it:

For further information about the $\mathrm{BEACH}$ program and General practice activity in Australia 1998-99, contact Associate Professor Helena Britt, Director, Family Medicine Research Centre, Acacia House, Westmead Hospital, Westmead NSW 2145. Telephone: (02) 9845 8150, fax: (02) 9845 8155, email: gpscu@fmru.org.au, or at the Website: www.fmru.org.au. 